\title{
Isolation, Characterization and Selection of Avermectin-Producing Streptomyces avermitilis Strains From Soil Samples
}

\author{
Samia Siddique ${ }^{1,{ }^{*}}$; Quratulain Syed ${ }^{2}$; Ahmad Adnan ${ }^{1}$; Fahim Ashraf Qureshi ${ }^{3}$ \\ ${ }^{1}$ Department of Chemistry, Government College University, Lahore, Pakistan \\ ${ }_{2}^{2}$ Food and Biotechnology Research Center, Pakistan Council of Scientific and Industrial Research Laboratories Complex Ferozepur, Lahore, Pakistan \\ 3 Office of Research, Innovation and Commercialization, Comsats Institute of Information and Technology, Islamabad, Pakistan \\ *Corresponding author: Samia Siddique, Department of Chemistry, Government College University Lahore, Pakistan. Tel/ Fax: +92-3334101261, E-mail: samiasiddique86@hotmail.com
}

Received: February 3, 2013; Revised: April 25, 2013; Accepted: May 9, 2013

\begin{abstract}
Background: Streptomyces avermitilis, belonging to Actinomycetes, is specialized for production of avermectin, used as an anthelmintic and insecticidal agent. It is mostly found in soil and its isolation is very crucial for medically important avermectin production.

Objectives: In the present study, 10 bacterial isolates lacking antimicrobial activities were isolated from the soil samples collected from different areas of Lahore, Pakistan.

Materials and Methods: Three distinctive localities of Lahore were opted for soil assortment to isolate S. avermitilis. About 50 isolates of Streptomyces species were attained through selective prescreening procedures. All of these isolates were studied for production of the secondary metabolite, avermectin. Different test like soluble pigment color and melanin formation were used for identification. Biochemical characterizations of those isolates closely resembling the control in morphological characteristics, soluble pigment color and melanin formation tests were performed.

Results:The 10 selected isolates were identified as the avermectin-producing strain by fermentation and characterized on ISP2 medium for aerial and reverse side mycelia color, soluble pigment color and melanin formation, in comparison with S. avermitilis DSM 41445. The best avermectin-producing isolate $\mathrm{S1}-\mathrm{C}(10.15 \mathrm{mg} / \mathrm{L})$ showed similar result as S. avermitilis DSM 41445, when subjected for culture characteristics analysis in different media along with biochemical characterization.

Conclusions: From the results, it was concluded that agricultural lands around Pakistan Council of Scientific and Industrial Research (PCSIR)Campus Lahore were rich sources of industrially important Streptomyces, especially S. avermitilis.
\end{abstract}

Keywords:Streptomyces; Anti-Infective Agents; Avermectin

\section{Background}

Streptomyces, belonging to the most profuse group of microorganisms in soil, the Actinomycetes, are aerobic and Gram-positive bacteria $(1,2)$. Their distribution and presence in soil is highly affected by geographical conditions of the soil like temperature, type, $\mathrm{pH}$, amount of organic materials, and moisture contents. The acidic environment-resistant groups are the most abundant of all Actinomycetes in the soil (3). However, they are less abundant in soils with alkaline $\mathrm{pH}(4)$ and are famous for their ability of producing industrially important enzymes and secondary metabolites during the fermentation process (5) as well as covering about $80 \%$ of antibiotic products (6). Screening and isolation of microorganisms producing secondary metabolites have been the main focus for several years (7).

Components of media affect the Streptomyces isolation. Media containing glycerol or starch as carbon sources and arginine, casein or nitrate as nitrogen sources will result in the best isolation. Different antifungal agents named nystatin, cycloheximide and pimaric in are usually employed during the isolation to obtain pure bacterial isolates. Identification of Streptomyces is based on the spore size, morphology, chains, pigmentation, physiological and biochemical characteristics, and antibiotic resistance (8).

Standard microbiological methods, analysis of biochemical markers, and DNA sequencing have also been employed for selective identification of genus and species of the isolated microbes (9). Streptomyces form stable filaments and are also capable of producing long chains of spores with aerial growth. Direct and non-direct methods of screening antibiotic producing strains have usually been employed for isolating a specific microbe. Direct screening of strains involves bio assay or some chemical methods, while non-direct screening involves correlation of the strain characteristics with antibiotic

Implication for health policy/practice/research/medical education:

Avermectin is one of the 16-membered macrocyclic lactone derivatives with anthelmintic and insecticidal potential, generated from S. avermitilis isolated from soil. It is used to control insect and mite pests of a range of agronomic, fruit, vegetable and ornamental crops. The main use of avermectin is controlling fire ants.

Copyright (C) 2014,Ahvaz Jundishapur University of Medical Sciences; Published by Kowsar Corp. This is an open-access article distributed under the terms of the Creative Commons Attribution License, which permits unrestricted use, distribution, and reproduction in any medium, provided the original work is properly cited. 
production (10-12). Streptomyces members are very important because of their ability to produce several types of secondary metabolites (13).

Streptomyces avermitilis, a Gram-positive bacteria, is specialized for formation of secondary metabolites, from which avermectinis used as an anthelmintic agents. Avermectin is one of the 16-membered macrocyclic lactone derivatives with anthelmintic and insecticidal potential, generated from $S$. avermitilis isolated from soil. It is used to control insects and mite pests of a range of agronomic, fruit, vegetable and ornamental crops. The main use of avermectin is controlling fire ants. Ivermectin, as emisynthetic derivative of avermectin, is widely used in veterinary for improved animal health as well as on chocerciasis eradication (14-16).

\section{Objectives}

The present study was conducted for isolation of S. avermitilis from the soil samples of different locations of Pakistan Council of Scientific and Industrial Research (PCSIR), Lahore, Pakistan, using various pretreatment methods. Different media were employed for screening of pure Streptomyces species. Antibacterial and antifungal activities of various isolates were also evaluated.

\section{Materials and Methods}

\subsection{Collection and Preparation of Soil Samples}

Different locations of PCSIR Lahore and Punjab University were selected for soil sampling. About $3 \mathrm{~cm}$ of each soil surface was removed with sterilized spatula and samples were stored in clean, dry and sterilized polythene bags at $40^{\circ} \mathrm{C}$ until pretreatment (17). For each soil sample, $1 \mathrm{~g}$ of soil was suspended in $100 \mathrm{~mL}$ of sterile saline and incubated at $28^{\circ} \mathrm{C}$ in orbital shaker for 30 minutes at $150 \mathrm{rpm}$. Soil samples were vortexed with the maximum speed and then allowed to stand for a few minutes. Serial dilutions up to 10-5 of each soil sample were made in sterile saline (18). For separation of spores from vegetative cells, test tube of dilution $10-5$ was placed in a $45^{\circ} \mathrm{C}$-water bath for 16 hours (13).

\subsection{Isolation of Streptomyces Colonies From the Soil Samples}

The media employed for isolation and enumeration of Actinomycetes were Actinomycete isolation agar medium (19): 5 g/L glycerol, 4 g/L sodium propionate, 2 g/L sodium casemate, $2 \mathrm{~g} / \mathrm{L} \mathrm{KH}_{2} \mathrm{PO}_{4}, 0.1 \mathrm{~g} / \mathrm{L}$ asparagine, $0.1 \mathrm{~g} / \mathrm{L} \mathrm{MgSO}_{4} .7$ $\mathrm{H}_{2} \mathrm{O}, 1 \mathrm{mg} \mathrm{FeSO}{ }_{4} .7 \mathrm{H}_{2} \mathrm{O}, 15 \mathrm{~g} / \mathrm{L}$ agar, $\mathrm{pH}=7.0$; Kuster's Agar medium (20): $10 \mathrm{~g} / \mathrm{L}$ Glycerol, $0.3 \mathrm{~g} / \mathrm{L}$ casein, $3 \mathrm{~g} / \mathrm{L} \mathrm{KNO}_{3}, 2$ $\mathrm{g} / \mathrm{L} \mathrm{K}_{2} \mathrm{HPO}_{4}, 2 \mathrm{~g} / \mathrm{L} \mathrm{NaCl}, 0.05 \mathrm{~g} / \mathrm{L} \mathrm{MgSO}_{4} .7 \mathrm{H}_{2} \mathrm{O}, 0.02 \mathrm{~g} / \mathrm{LCa}-$ $\mathrm{CO}_{3}, 0.01 \mathrm{~g} / \mathrm{L} \mathrm{FeSO}_{4} .7 \mathrm{H}_{2} \mathrm{O}, 16 \mathrm{~g} / \mathrm{L}$ agar, $\mathrm{pH}=7 \pm 1$; glycerol casein $\mathrm{KNO}_{3}$ agar medium (1): $10 \mathrm{~g} / \mathrm{L}$ Glycerol, $0.3 \mathrm{~g} / \mathrm{L}$ casein, $2 \mathrm{~g} / \mathrm{L} \mathrm{KNO}_{3}, 2 \mathrm{~g} / \mathrm{LK}_{2} \mathrm{HPO}_{4}, 2 \mathrm{~g} / \mathrm{L} \mathrm{NaCl}, 0.05 \mathrm{~g} / \mathrm{L} \mathrm{MgSO}_{4} .7 \mathrm{H}_{2} \mathrm{O}$,
$0.02 \mathrm{~g} / \mathrm{LCaCO}_{3}, 0.01 \mathrm{~g} / \mathrm{L} \mathrm{FeSO}_{4} .7 \mathrm{H}_{2} \mathrm{O}, 18 \mathrm{~g} / \mathrm{L}$ agar, $\mathrm{pH}=7.8$; and starch casein agar medium (21): $10 \mathrm{~g} / \mathrm{L}$ starch, $1 \mathrm{~g} / \mathrm{L}$ casein powder, $15 \mathrm{~g} / \mathrm{L}$ agar, $50 \%$ sea water, $\mathrm{pH}=7.2 \pm 0.2$. Each of these media was supplemented with nystatin at concentration of $0.050 \mathrm{mg} / \mathrm{mL}$ as the antifungal agent $(22,23)$.

Dilutions of each soil sample were spread on the plates containing the isolation media and incubated at $28^{\circ} \mathrm{C}$ for 7-10 days. Individual colonies from the mixed cultures were then transformed onto yeast extract-malt extract agar slants (13). Pure cultures were obtained by multiple streaking on yeast extract malt extract glucose medium (YMG) agar slants (24): yeast extract, 4 g/L; malt extract, 10 $\mathrm{g} / \mathrm{L}$; glucose, $4 \mathrm{~g} / \mathrm{L}$; agar, $20 \mathrm{~g} / \mathrm{L} ; \mathrm{pH}=7.3$. Finally, the Streptomyces isolation medium consisting of glucose: $5.0 \mathrm{~g} / \mathrm{L}$, L-glutamic: $4.0, \mathrm{KH}_{2} \mathrm{PO}_{4}$ : $1.0, \mathrm{MgSO}_{4} .7 \mathrm{H}_{2} \mathrm{O}: 0.7, \mathrm{NaCl}: 1.0$, $\mathrm{FeSO}_{4} \cdot 7 \mathrm{H}_{2} \mathrm{O}: 3.0 \mathrm{mg}$, and agar: $25 \mathrm{~g} / \mathrm{L}$, was used for purification of Streptomyces colonies (20) supplemented with nystatin at concentration of $0.050 \mathrm{mg} / \mathrm{mL}$ as the antifungal agent $(22,23)$.

\subsection{Study of Antimicrobial Activities}

Antimicrobial activities of the isolated Streptomyces strains were studied against different bacteria (Escherichia coli, Enterobacter aerogenes, Staphylococcus. aureus, Pseudomonas aerogenosa and Bacillus subtilis), fungi (Aspergillus niger, Rhizopus oligosporus) and yeast (Candida albicans). All these strains were obtained from the Food and Biotechnology Department of PCSIR and cultured in nutrient broth for 24 hours at $37^{\circ} \mathrm{C}$ (13). For yeast and fungi cultures, the incubation period was five days.

Well diffusion method was used for studying antimicrobial activities of the isolates. Wells were separately created in each plate using the sterilized borer, already seeded with $300 \mu \mathrm{L}$ of the test organisms (25). Each well was then filled with $300 \mu \mathrm{L}$ of supernatant of each isolate dilution and kept for at least one hour to ensure the complete diffusion of dilution into the nutrient agar medium in each plate. Diameters of the zones, formed after the incubation periods of 24 and 48 hours at $37^{\circ} \mathrm{C}$, were measured (19). Control plates were also made, empty of the isolated strains, to investigate the normal growth of Streptomyces. Plates of the reference S. avermitilis DSM 41445 were also prepared for comparative analysis.

\subsection{Characterization of the Isolated Colonies}

\subsubsection{Gram Staining}

Gram staining of the isolates was performed according to the method described earlier (18).

\subsubsection{Avermectin Production}

All the purified isolates were tested for production of avermectin through fermentation, along with S. avermiti- 
lis DSM 41445 for comparative study.

\subsection{Seed Medium}

The cultures were maintained on medium 65 (glucose: $4.0 \mathrm{~g} / \mathrm{L}$, yeast extract: $4.0 \mathrm{~g} / \mathrm{L}$, malt extract: $10.0 \mathrm{~g} / \mathrm{L}, \mathrm{CaCO}_{3}$ : $2.0 \mathrm{~g} / \mathrm{L}$, and agar: $12 \mathrm{~g} / \mathrm{L}$ ) as specified by Deutsche Sammlung von Mikroorganis men und Zellkulturen (DSMZ) Loopful culture of the strain was scraped from the nutrient agar slant and inoculated into $50 \mathrm{~mL}$ of yeast malt glucose (YMG) medium consisting of glucose: 4.0, yeast extract: 4.0, malt extract: 10.0 and CaCO3: 2.0 (g/L in distilled water) in a $250-\mathrm{mL}$ shake flask. After wards, it was incubated in an orbital shaker at 150x g for 16-18hours at $30^{\circ} \mathrm{C}$ in a water bath shaker (Eyela, Japan). pH of the inoculum was adjusted at $7.2 \pm 2(26)$.

\subsection{Avermectin Production}

Production of avermectin B1b from the soil isolates was studied individually in synthetic medium 2 (SM2) growth medium. Each production medium was inoculated with $5 \mathrm{~mL}(10 \% \mathrm{v} / \mathrm{v})$ of inoculum medium separately. After transferring the seed medium, each growth medium was incubated at $30^{\circ} \mathrm{C}$ in the water bath shaker for 10 days at 150x g. Composition of the growth medium was soluble corn starch: 50.0, KCl: 0.1, NaCl: 0.5, yeast extract: 2.0, $\mathrm{MgSO}_{4} .7 \mathrm{H}_{2} \mathrm{O}: 0.1, \mathrm{CaCO}_{3}$ : 0.8 and $\alpha$-amylase: 0.1 (all in $\mathrm{g} / \mathrm{L}$ ). $\mathrm{pH}$ of the medium was adjusted at $7.2 \pm 0.2$. All the experiments were separately performed in the shake flasks containing $50 \mathrm{~mL}$ of the fermentation medium (26).

\subsection{Extraction of Avermectin $B 1 b$}

The fermentation broth from each fermentation flask was centrifuged (H-1500FR Japan) at $40^{\circ} \mathrm{C}$ for 20 minutes at $8000 \mathrm{x}$ g. Since avermectin is an intracellular molecule, the cell biomass was separated and the supernatant was discarded. The cell biomass in the form of pallet was mixed with an appropriate amount of methanol to completely dissolve it. The mixture was centrifuged again and the supernatant was collected for avermectin analysis by high-performance liquid chromatography HPLC (26).

\subsection{HPLC Analysis of Avermectin B1b}

Concentrations of the avermectin components were determined quantitatively by reverse phase HPLC (LC-2080, Shimadzu, India). About $20 \mu \mathrm{L}$ of each sample was run into the HPLC. The samples were separated on C18 column (SMA C-18) and detector (UV Variable Wavelength Detector STD-M20A, Shimadzu, India) and eluted by methanol: acetonitrile $(98: 2 \mathrm{v} / \mathrm{v})$ at a flow rate of $0.5 \mathrm{~mL} / \mathrm{min}$ with a UV absorbance at $246 \mathrm{~nm}$ (27).

\subsubsection{Biological Testing}

The isolates with avermectin B1b production were further identified by certain biological tests including growth temperature range test, hemolysis test, urea hydrolysis, oxalate utilization test, $\mathrm{H}_{2} \mathrm{~S}$ production test, acid production test, carbohydrate assimilation test, amylolytic activity and proteolytic activity, as recommended by International Streptomyces Project (ISP). Utilization of different carbon sources such as glucose, starch, mannitol, fructose, soluble corn starch, potato starch and maltose, and nitrogen sources namely malt extract, yeast extract, peptone, urea and lemco powder were also tested on Streptomyces isolation medium (19). The medium was supplemented with nystatin at concentration of 0.050 $\mathrm{mg} / \mathrm{mL}$ as the antifungal agent $(22,23)$. Plates of the reference culture of DSM S. avermitilis 41445 were also prepared for comparative study.

\section{Results}

Only 10 soil isolated strains were found to lack antimicrobial properties. These 10 isolates, when tested for secondary metabolite production through submerged fermentation, were capable of avermectin production as is shown in Table 2. The soil isolate named S1-C gave maximum (10.15 mg/L) avermectin production. Morphological characteristics of these isolates revealed that they closely resembled S. avermitilis species, when compared with the control strain S. avermitilis DSM 41445. Therefore the 10 isolates were grouped as S. avermitilis. The percentage of color production by these 10 isolates in the form of soluble pigments, varied within a color series. Production of soluble pigments in dark yellow, yellow, pale yellow and brownish yellow was about $10 \%, 60 \%, 20 \%$ and $10 \%$, respectively. Rate of melanin production for these 10 isolates was $100 \%$. The aerial mycelium color was dark grey (10\%), grey $(70 \%)$ and light grey (20\%). Similarly, the reverse side color was moderate grey (10\%), grey (50\%), light grey (20\%), and white to grey (20\%).

Table 3 reveals that in oatmeal agar medium (ISP3) and yeast extract-malt extract agar (ISP2), S1-C and control showed same characteristic. In nutrient agar medium, both strains showed same growth patterns. The difference was in the color of aerial mycelium and the reverse side color, which was also very minute. In other media, the color ranged from grey to light grey. In DSMZ (Deutsche Sammlung von Mikroorganismen and Zellkulturen) specified medium 65, color varied from yellow to light yellow with excellent growth of control as compared to the isolated strain showing growth of good level.

\section{Discussion}

The present study was conducted for isolation of Streptomyces from the soil samples taken from different locations of PCSIR and other locations of Lahore. The main emphasize was on selection of Streptomyces spp., producing the avermectins as anthelmintic agent.

About 50 soil samples were collected for isolation of the desired Streptomyces. All the isolated were tested 
against eight test microorganisms, three of which were Gram-negative (E. aerogenes, E. coli, P. aerogenosa) and two Gram-positive (S. aureus, B. subtilis). Two fungal species ( $R$. oligosporus, A. niger) and one yeast (C. albicans) were also used to test the antimicrobial activities of the isolates. Patterns of antimicrobial activities of all these isolated are given in Table 1 showing that 10 isolates were completely resistant to all the test microbes and did not show any activity. It was reported in an earlier research that S. avermitilis lacks characteristic antimicrobial activities (28). In the present study, only 10 did not show antimicrobial activities. These strains were supposed to be $S$. avermitilis, producing the avermectin compound, lacking antibacterial and antifungal activities. The control plates were also prepared for comparison and confirmatory studies.

All the 10 isolates belonged to the Streptomyces genus, when examined morphologically on ISP 2 Yeast extractmalt extract medium $(13,24)$. In a previous study, researchers found that Streptomyces isolates showed 13.3\% melanin pigment production. Furthermore, the color variation for aerial mycelium was brown-yellow (80\%), yellow (6.6\%) and violet (13.3\%). They noticed 93.3\% brownish-yellow and 6.6\% violet in reverse side mycelium (13). The morphological characterization of Streptomyces isolates normally relied upon the formation and color of aerial and substrate mycelium, soluble pigment formation, and spore characteristics (8).

The fermentation broth obtained during secondary metabolite production lacked antibacterial and antifungal activities. It is reported that avermectins are a series of macrocyclic lactones, lacking significant antibacterial and antifungal activities $(29,30)$. In another research, it was reported that $S$. avermitilis was specialized for its ability to produce secondary metabolites, which was potentially anthelmintic and named avermectin $(1,30)$. In the present study, all the 10 strains were then tested for production of secondary metabolite through fermentation. It was found that these isolates produced avermectin in very small quantities, as is shown in Table 2 . The maximum avermectin production $(10.15 \mathrm{mg} / \mathrm{L})$ was presented by the soil isolate designated as S1-C.

Culture characteristics of S. avermitilis 173 on different media were observed, which resulted in different growth patterns and mycelia colors (30). In the present study, the same variations were observed. Isolated S1-C strain showed the maximum avermectin production and was selected for studying the cultural characteristics on different media along with the control strain DSM S. avermitilis.

Morphological and biochemical characteristics derived from the physiological test, have been used for taxonomic classification and identification of different strain of Streptomyces $(20,31)$. In the present study, selective avermectin-producing S1-C Streptomyces species were subjected to different biochemical tests for identification, and later they were compared with that of the control strain, as shown in Table 4. The S1-C strain isolated at mesophilic temperature $\left(25-37^{\circ} \mathrm{C}\right)$ was in agreement with results of other researchers, showing the isolation of most of the Streptomyces to be appropriate at these conditions. Production of avermectin from S1-C isolate at neutrophilic medium with $\mathrm{pH}$ range of 7.0-7.5 confirmed the strain dependency to Streptomyces(8).The S1-C strain and control showed same results in all biochemical tests.

\begin{tabular}{|c|c|c|c|c|c|c|c|c|c|}
\hline \multicolumn{10}{|c|}{ Zone of Inhibition, mm } \\
\hline \multicolumn{10}{|c|}{ Streptomyces Isolation Agar Medium } \\
\hline $\begin{array}{l}\text { Serial } \\
\text { Number }\end{array}$ & $\begin{array}{l}\text { Soil Iso- } \\
\text { late }\end{array}$ & $\begin{array}{c}\text { Esch- } \\
\text { erichia } \\
\text { coli }\end{array}$ & $\begin{array}{c}\text { Entero- } \\
\text { bacter } \\
\text { aerogenes }\end{array}$ & $\begin{array}{l}\text { Staphy- } \\
\text { lococcus } \\
\text {.aureus }\end{array}$ & $\begin{array}{l}\text { Pseudomo- } \\
\text { nas.aero- } \\
\text { genosa }\end{array}$ & $\begin{array}{l}\text { Bacillus } \\
\text {.subtilis }\end{array}$ & $\begin{array}{l}\text { Aspergil- } \\
\text { lus. niger }\end{array}$ & $\begin{array}{l}\text { Rhizopus . } \\
\text { oligosporus }\end{array}$ & $\begin{array}{l}\text { Candida } \\
\text { albicans }\end{array}$ \\
\hline 1 & S1-A & - & - & - & - & + & - & - & - \\
\hline 2 & S1-B & + & + & + & - & - & - & + & + \\
\hline 3 & S1-C & - & - & - & - & - & - & - & - \\
\hline 4 & S1-D & - & - & + & + & ++ & - & - & - \\
\hline 5 & S1-E & - & - & ++ & - & + & ++ & + & + \\
\hline 6 & S1-F & ++ & + & - & +++ & - & - & + & + \\
\hline 7 & S1-G & - & - & + & - & + & - & - & - \\
\hline 8 & S1-H & - & - & - & + & - & ++ & - & - \\
\hline 9 & S1-I & ++ & ++ & + & + & - & - & + & + \\
\hline 10 & S1-J & - & - & - & - & - & - & - & - \\
\hline 11 & S2-A & - & - & - & + & + & - & ++ & - \\
\hline 12 & S2-B & - & - & ++ & - & - & - & - & +++ \\
\hline 13 & S2-C & + & - & - & + & - & ++ & - & - \\
\hline 14 & S2-D & - & + & - & - & + & & & \\
\hline 15 & S2-E & - & - & - & - & - & - & - & - \\
\hline 16 & S2-F & - & - & + & - & - & + & - & - \\
\hline
\end{tabular}


Siddique S et al.

\begin{tabular}{|c|c|c|c|c|c|c|c|c|c|}
\hline 17 & S2-G & - & + & ++ & + & - & - & - & + \\
\hline 18 & $\mathrm{~S} 2-\mathrm{H}$ & + & - & + & - & - & - & ++ & - \\
\hline 19 & S2-I & + & - & + & - & + & - & - & ++ \\
\hline 20 & S2-J & - & - & - & - & - & - & - & - \\
\hline 21 & S3-A & - & - & + & - & + & - & + & - \\
\hline 22 & S3-B & - & - & + & - & ++ & - & + & - \\
\hline 23 & S3-C & ++ & + & - & + & - & ++ & - & + \\
\hline 24 & S3-D & ++ & + & - & + & - & ++ & - & - \\
\hline 25 & S3-E & - & - & - & - & - & - & - & - \\
\hline 26 & S3-F & - & - & + & - & + & - & + & - \\
\hline 27 & S3-G & - & + & + & + & - & - & - & - \\
\hline 28 & S3-H & - & ++ & - & - & - & + & + & - \\
\hline 29 & S3-I & - & - & - & - & - & - & - & - \\
\hline 30 & S3-J & ++ & + & - & - & +++ & - & - & + \\
\hline 31 & S4-A & + & ++ & ++ & - & + & - & - & + \\
\hline 32 & S4-B & - & - & + & ++ & - & + & + & - \\
\hline 33 & S4-C & + & + & ++ & - & - & - & - & + \\
\hline 34 & S4-D & ++ & + & - & + & - & ++ & - & + \\
\hline 35 & S4-E & + & - & - & + & - & ++ & - & - \\
\hline 36 & S4-F & - & - & - & - & - & - & - & - \\
\hline 37 & S4-G & + & - & - & + & - & ++ & - & - \\
\hline 38 & S4-H & + & - & ++ & - & + & - & - & + \\
\hline 39 & S4-I & + & ++ & ++ & - & + & - & - & + \\
\hline 40 & S4-J & - & - & - & - & - & - & - & - \\
\hline 41 & S5-A & + & - & - & + & - & ++ & - & - \\
\hline 42 & S5-B & ++ & + & - & + & - & ++ & - & + \\
\hline 43 & S5-C & - & - & - & - & - & - & - & - \\
\hline 44 & S5-D & + & ++ & ++ & - & + & - & - & + \\
\hline 45 & S5-E & + & - & + & ++ & + & - & - & + \\
\hline 46 & S5-F & ++ & + & - & +++ & - & - & + & + \\
\hline 47 & S5-G & + & - & - & + & - & ++ & - & - \\
\hline 48 & S5-H & - & - & - & - & - & - & - & - \\
\hline 49 & S5-I & + & - & ++ & - & + & - & - & + \\
\hline 50 & S5-J & ++ & + & - & + & - & ++ & - & + \\
\hline 51 & Control & - & - & - & - & - & - & - & - \\
\hline
\end{tabular}

\begin{tabular}{lcc}
\hline Table 2. Secondary Metabolite (Avermectin) Production of Selected Isolates & \\
\hline Serial Number & Soil Isolate & Avermectin Production, mg/L \\
\hline $\mathbf{1}$ & S1-C ${ }^{\mathrm{C}}$ & $10.15 \pm 0.04$ \\
$\mathbf{2}$ & S1-J & $5.0 \pm 0.05$ \\
$\mathbf{3}$ & S2-E & $7.35 \pm 0.01$ \\
$\mathbf{4}$ & S2-J & $6.29 \pm 0.09$ \\
$\mathbf{5}$ & S3-E & $8.35 \pm 0.06$ \\
$\mathbf{6}$ & S3-I & $6.0 \pm 0.011$ \\
$\mathbf{7}$ & S4-F & $3.86 \pm 0.02$ \\
$\mathbf{8}$ & S4-J & $5.78 \pm 0.01$ \\
$\mathbf{9}$ & S5-C & $5.64 \pm 0.02$ \\
$\mathbf{1 0}$ & S5-H & $8.65 \pm 0.07$ \\
$\mathbf{1 1}$ & Control & $17.0 \pm 0.03$ \\
\hline
\end{tabular}

\footnotetext{
${ }^{\mathrm{a}}$ Data are presented as mean \pm SD.

b Shake flask fermentation at $\mathrm{pH}$ 7.0, temperature: $31^{\circ} \mathrm{C}$. Each value is an average of three replicates.

${ }^{\mathrm{c}}$ Designation of the best avermectin producing strain.
} 
Siddique S et al.

\begin{tabular}{|c|c|c|c|c|c|c|c|}
\hline \multirow{2}{*}{$\begin{array}{l}\text { Serial } \\
\text { Number }\end{array}$} & \multirow[t]{2}{*}{ Type of Medium } & \multicolumn{2}{|c|}{ Growth } & \multicolumn{2}{|c|}{ Aerial Mycelium } & \multicolumn{2}{|c|}{ Reverse Side Color } \\
\hline & & S1-C & Control & S1-C & Control & S1-C & Control \\
\hline 1 & Nutrient agar & Good & Good & Dark yellow & Light yellow & Light yellow & $\begin{array}{l}\text { White to yel- } \\
\text { low }\end{array}$ \\
\hline 2 & $\begin{array}{l}\text { Yeast extract malt } \\
\text { extract agar (ISP2) }\end{array}$ & Good & Good & Dark grey & Dark grey & Moderategrey & $\begin{array}{l}\text { Moderate to } \\
\text { light grey }\end{array}$ \\
\hline 3 & $\begin{array}{c}\text { Inorganic salt-starch } \\
\text { agar (ISP4) }\end{array}$ & Moderate & Excellent & Grey & Dark grey & $\begin{array}{l}\text { Light cinna- } \\
\text { mon }\end{array}$ & Light grey \\
\hline 4 & PDA agar & Moderate & Good & $\begin{array}{l}\text { White to yel- } \\
\text { low }\end{array}$ & Dark yellow & Light yellow & Pale yellow \\
\hline 5 & Oatmeal agar (ISP3) & Good & Good & Grey & Grey & White to grey & White to grey \\
\hline 6 & Bennett's agar & Good & Very Good & Grey & Grey & Light grey & Light grey \\
\hline 7 & $\begin{array}{l}\text { Casein enzymich- } \\
\text { ydrolysate-yeast } \\
\text { extract (ISP1) }\end{array}$ & Good & Good & Light grey & Light grey & Light grey & White to grey \\
\hline 8 & DSMZ medium 65 & Good & Excellent & Yellow & Light yellow & Light yellow & $\begin{array}{c}\text { White to yel- } \\
\text { low }\end{array}$ \\
\hline
\end{tabular}

\begin{tabular}{|c|c|c|c|}
\hline Serial Number & Properties & S1-C Streptomyces spp. & Control \\
\hline $\mathbf{A}$ & Morphological characteristics & & \\
\hline 1 & Spore morphology & Oval shaped, smooth & Smooth \\
\hline 2 & Color of aerial mycelium & Dark grey & Grey \\
\hline 3 & Color of substrate mycelium & Grey & Light grey \\
\hline 4 & Gram’s reaction & Gram positive & Gram positive \\
\hline B & Biochemical characteristics & & \\
\hline 1 & Growth temperature range & $28-37^{\circ} \mathrm{C}$ & $28-37^{\circ} \mathrm{C}$ \\
\hline 2 & $\mathrm{pH}$ range & 7.0-7.5 & $7.0-7.5$ \\
\hline 2 & Nitrate reduction test & - & - \\
\hline 3 & Milk coagulation and peptonization & + & + \\
\hline 4 & Gelatin liquefication & + & + \\
\hline 5 & $\mathrm{H}_{2} \mathrm{~S}$ production test & - & - \\
\hline \multicolumn{4}{|l|}{6} \\
\hline & N-source utilization & & \\
\hline & Yeast extract & + & ++ \\
\hline & Malt extract & + & + \\
\hline & Peptone & + & + \\
\hline & Urea & + & + \\
\hline & Lemco powder & + & + \\
\hline \multicolumn{4}{|l|}{7} \\
\hline & C-source utilization & & \\
\hline & Glucose & + & + \\
\hline & Soluble corn starch & ++ & ++ \\
\hline & Maltose & + & + \\
\hline & Lactose & + & + \\
\hline & Mannitol & + & + \\
\hline & Wheat powder & + & + \\
\hline & Potato starch & ++ & ++ \\
\hline
\end{tabular}

\section{Acknowledgements}

The Research is a part of PhD thesis of first author. The research was conducted at PCSIR Labs. Complex Lahore and completely funded by Higher Education Commission (HEC), Islamabad, Pakistan.

Jundishapur J Microbiol. 2014;7(6):e10366 


\section{Authors' Contribution}

Experimental work and data analysis was done by Samia Siddique under the supervision of Dr. Fahim Ashraf Qureshi. Technical support and valuable information during the research work were provided by Dr. Quratulain Asad and Dr. Ahmad Adnan.

\section{Financial Disclosure}

All the financial support was provides by Higher Education Commission (HEC) of Islamabad, Pakistan.

\section{Funding/Support}

The financial support and opportunity to perform the experimental work were provided by Government College University GCU, Lahore. Funding was provided by Higher Education Commission of Pakistan. Pakistan Council of Scientific and Industrial Research Laboratories provided the facilities to conduct the entire research work.

\section{References}

1. Kim SB, Goodfellow M. Streptomyces avermitilis sp. nov., nom rev., a taxonomic home for the avermectin-producing streptomycetes. Int J Syst Evol Microbiol. 2002;52(Pt 6):2011-4.

2. Kuster E. The Actinomycetes. In: Burges A, Raw F editors. Soil biology.. London: Academic Press; 1968. pp. 111-24.

3. Davies FL, Williams ST. Studies on the ecology of actinomycetes in soil: I. The occurrence and distribution of actinomycetes in a pine forest soil. Soil Biol Biochem. 1970;2(4):227-38.

4. Mitsuiki S, Sakai M, Moriyama Y, Goto M, Furukawa K. Purification and some properties of a keratinolytic enzyme from an alkaliphilic Nocardiopsis sp. TOA-1. Biosci Biotechnol Biochem. 2002;66(1):164-7.

5. Tsujibo H, Kubota T, Yamamoto M, Miyamoto K, Inamori Y. Characterization of chitinase genes from an alkaliphilic actinomycete, Nocardiopsis prasina OPC-131. Appl Environ Microbiol. 2003;69(2):894-900.

6. Hopwood DA, Buttner MJ, Bibb MJ, Kieser T, Charter KF. Antibiotic production by Streptomyces. Pract Streptomyces Genet. 2000;1:142.

7. Ouhdouch Y, Barakate M, Finance C. Actinomycetes of Moroccan habitats: isolation and screening for antifungal activities. Eur $J$ Soil Biol. 2001;37(2):69-74.

8. Awad HM, Kamal YI, M.El-Nakkadi AEM. Isolation, screening and identification of newly isolated soil Streptomyces (Streptomyces sp. NRC-35) for $\beta$-Lactamase inhibitor production. J World Apllied Sci. 2009;7(5):637-46.

9. Rossello-Mora R, Amann R. The species concept for prokaryotes. FEMS Microbiol Rev. 2001;25(1):39-67.

10. Smith JE. Perspective in biotechnology and applied microbiology; 1989.

11. Vandemme EJ. Biotechnology of Industrial Antibiotics.New York: Marcel Dekker Inc.; 1948.

12. Bu'Lock J. Basic Biotechnology:: Academic Press; 1987.

13. Ceylan O, Okmen G, Ugur A. Isolation of soil Streptomyces as source antibiotics active against antibiotic-resistance bacteria. EurAsian J Biosci. 2008;2:73-82.
14. Ikeda H, Ishikawa J, Hanamoto A, Shinose M, Kikuchi H, Shiba T, et al. Complete genome sequence and comparative analysis of the industrial microorganism Streptomyces avermitilis. Nat Biotechnol. 2003;21(5):526-31.

15. Yin P, Wang YH, Zhang SL, Chu J, Zhuang YP, Wang ML, et al. Isolation of soluble proteins from an industrial strain Streptomyces avermitilis in complex culture medium for two-dimensional gel electrophoresis. J Microbiol Methods. 2008;73(2):105-10.

16. Kitani S, Miyamoto KT, Takamatsu S, Herawati E, Iguchi H, Nishitomi K, et al. Avenolide, a Streptomyces hormone controlling antibiotic production in Streptomyces avermitilis. Proc Natl Acad Sci US A. 2011;108(39):16410-5.

17. Arifuzzaman M, Khatun MR, Rahman H. Isolation and screening of Actinomycetes from Sundarbans soil for antibacterial activity. African J Biotechnol. 2010;9(29):4615-9.

18. Kumar N, Singh RK, Mishra SK, Singh AK, Pachouri UC. Isolation and screening of soil Actinomycetes as source of antibiotics active against bacteria. Int J Microbiol. 2010;2(2):12-6.

19. Balagurunathan R, Subramanian A. Antagonistic Streptomyces from marine sediments. Advance Biosci. 1992;20:71-6.

20. Wellington EMH, Cross T. Taxonomy of antibiotic producing Actinomycetes and new approaches towards their selective isolation. In: Bushell ME editor. Progress in industrial Microbiology. Amsterdam: Elsevier; 1983. p. 36.

21. Phillips GB, Hanel E, Jr.. Control of mold contaminants on solid media by the use of actidione. J Bacteriol. 1950;60(1):104-5.

22. Porter JN, Wilhelm JJ, Tresner HD. Method for the preferential isolation of Actinomycetes from soils. Appl Microbiol. 1960;8:174-8.

23. Shirling EB, Gottlieb D. Method for characterization of Streptomyces species. Int J System Bacteriol. 1966;16:312-40.

24. Romero J, Liras P, Martín JF. Dissociation of cephamycin and clavulanic acid biosynthesis in Streptomyces clavuligerus. Appl Microbiol Biotechnol.1984;20(5):318-25.

25. Chen Z, Wen J, Song Y, Wen Y, Li J. Enhancement and selective production of avermectin B by recombinants of Streptomyces avermitilis via intraspecific protoplast fusion. Chin Sci Bull. 2007;52(5):616-22.

26. Siddique S, Syed Q, Adnan A, Nadeem M, Irfan M, Ashraf Qureshi F. Production of Avermectin B1b From Streptomyces avermitilis 41445 by Batch Submerged Fermentation. Jundishapur JMicrobiol. 2013;6(8).

27. Burg RW, Miller BM, Baker EE, Birnbaum J, Currie SA, Hartman $\mathrm{R}$, et al. Avermectins, new family of potent anthelmintic agents: producing organism and fermentation. Antimicrob Agents Chemother. 1979;15(3):361-7.

28. Yong JH, Byeon WH. Alternative production of avermectin components in Streptomyces avermitilis by gene replacement. J Microbiol. 2005;43(3):277-84.

29. Egerton JR, Ostlind DA, Blair LS, Eary CH, Suhayda D, Cifelli S, et al. Avermectins, new family of potent anthelmintic agents: efficacy of the B1a component. Antimicrob Agents Chemother. 1979;15(3):372-8.

30. Xiong LX, Li JZ, Wang HL. Streptomyces avermitilis from marine. JEnviron Sci (China). 2005;17(1):123-5.

31. Goodfellow M, Ferguson EV, Sanglier JJ. Numerical classification and identification of Streptomyces species--a review. Gene. 1992;115(1-2):225-33. 